перспективы развития новых направлений судебных экспертиз в России и за рубежом: Материалы международной научно-практической конференции. - Калининград, 2003.

6. Федоренко Е.Ю. Судебно-психологическая экспертиза в гражданском и уголовном процессе: учебно-методическое пособие / Е.Ю. Федоренко, А.А. Лопатин // Электрон, издан. - Красноярск: Сиб.федер. ун-т., 2012.

7. Постановление Пленума Верховного Суда РФ от 01.02.2011 № 1 (ред. от 29.11.2016) «О судебной практике применения законодательства, регламентирующего особенности уголовной ответственности и наказания несовершеннолетних» // Бюллетень Верховного Суда РФ. 2011. № 4.

8. Сафуанов Ф.С. Судебно-психологическая экспертиза: учебник для вузов. 2-е изд., перераб и доп. М.: Юрайт. -2019.

9. Сорокотягин И.Н. Судебная экспертиза: учебник и практикум для бакалавриата и специалитета / И Н. Сорокотягин, Д.А. Сорокотягина. - М.: Юрайт, 2019.

\title{
Рогава И.Г., Волкова О.В. \\ К вопросу об использовании зарубежного опыта в применении инновационных технологий при расследовании преступлений
}

Ростовский филиал «Российская таможенная академия» (Россия, Ростов-на-Дону)

doi: $10.18411 / \mathrm{j}-05-2021-195$

\section{Аннотация}

В рамках статьи рассматриваются инновационные технологии, которые применяются в криминалистике в США, Индии, Швейцарии и других зарубежных странах. В частности, приводится успешный опыт использования таких новых криминалистических технологий и методик, как географическая криминалистика, микробиологический анализ отпечатков пальцев, Микробиологическая идентификация, система HirisPlex, виртуальная аутопсия, 3D-фотограммметрия. Делаются выводы о возможности внедрения рассмотренных научных достижений и передовых технологий в криминалистику Российской Федерации.

Ключевые слова: инновационных технологии, криминалистика, зарубежные страны, расследование и раскрытие преступлений, зарубежная криминалистика.

\section{Abstract}

Article discusses innovative technologies that are used in forensic science in the USA, India, Switzerland and other foreign countries. In particular, a successful experience of using such new forensic technologies and techniques as geographic forensics, microbiological analysis of fingerprints, microbiological identification, HirisPlex system, virtual autopsy, 3D photogrammetry is presented. Conclusions are drawn about the possibility of introducing the considered scientific achievements and advanced technologies into the forensic science of the Russian Federation.

Keywords: innovative technologies, criminalistics, foreign countries, investigation and detection of crimes, foreign criminalistics.

Развитие научно-технического прогресса сказывается на совершенствовании криминалистических приемов и способов, позволяющих решать вопросы раскрытия и расследования преступлений. Достижения последних лет в области криминалистики позволяют использовать передовые технологии, облегчающие работу полиции с учетом безопасности и эффективности. Несмотря на то, что в обществе идут споры относительно применение тех или иных криминалистических методов, которые связаны с неприкосновенностью частной жизни, с этической составляющей, криминалистические технологии часто являются передовыми и инновационными, особенно в области трудно раскрываемых дел, связанных со случаями сексуального насилия, с убийствами. 
Рассмотрим несколько инновационных технологий, которые используются в зарубежной криминалистике и могут применяться и частично применяются российскими криминалистами при расследовании преступлений.

Например, в Соединённых Штатах Америки применяется метод географической криминалистики, сущность его базируется на определении отношений изотопов кислорода и водорода, которые находятся в человеческих тканях - в материалах или волосах. Такой показатель привязан к географическому месту нахождения лица, он определяется изотопический свойствам воды, которая присутствует на человеке частички изотопов воды всегда присутствуют в волосах [1]. Такая методология позволяет отслеживать перемещение человека в пространстве и успешно применяется при раскрытии серийных преступлений.

Другой инновационной технологией является методика распознавания лиц, она достаточно спорна с технической точки зрения, но, тем не менее, зарубежные криминалисты с успехом используют ее при отсутствии отпечатков пальцев или иных средств идентификации. Эффективность действия такой методики зависит от наполняемости информационной базы, которая занимается анализом распознавания лиц. Инструмент является эффективным в том случае, если присутствуют чёткие изображения, в этом случае идентификация получается стопроцентной. Такая технология распознавания лиц является повседневным инструментом в процессе разблокировки мобильных телефонов, при добавлении тегов к фотографиям в социальных сетях, её используют Amazon, правоохранительные органы Чикаго, ЛосАнджелеса и Нью-Йорка при невозможности установить личность по другим признакам [2, с. 233]. Но споры вызывает нарушение конфиденциальности, иногда программа выдает ложные совпадения.

Например, при взрыве на Бостонском марафоне тестировалась три системы распознавания лица, среди которых только одна смогла идентифицировать Джохара Царнаева, одного из совершивших преступление, при этом Тамерлана Царнаева система идентификации лиц не смогла распознать, поскольку он был в очках [3]. Такая технология является очень перспективной, поскольку качество изображения из года в год улучшается, и система, которая в настоящее время основывается на нейронных сетях, является самообучаемый.

Другая технология базируется на микробиологическом анализе отпечатков пальцев. Сама методология использования отпечатков пальцев не является новой, но учёные медицинского центра Амстердамского университета опубликовали научные результаты исследований, в которых доказали важность использования отпечатков пальцев при получении широкого круга информации, включая рацион питания преступника, Анализируя белки и жиры, которые секретируют кожа, исследователи сделали вывод, что по отпечаткам пальцев можно отследить пользование насильниками презервативов, и даже производителя этих средств, а далее - места продаж. Использование ДНК в будущем может позволить составлять генетический профиль подозреваемого человека, а уже на этой основе криминалисты будут иметь материал для составления физического облика преступника.

Новацией является прогноз установления цвета глаз и волос, с этим связано перспективное направление - фенотипирование, это судебная процедура, позволяющая установить цвет волос и глаз подозреваемого. Прогноз цвета глаз и волос дает возможность не обращаться к ДНК-профилю человека, а использовать только те генетические маркеры, которые дают возможность предсказать наличие цвета волос. Для этого используется система HirisPlex - возможности системы таковы, что можно распознать черноволосых людей с точностью до $90 \%$ как европейского, так и неевропейского происхождения [4]. Такой инструмент судебной экспертизы может стать широко используемым с развитием генетическая криминалистики. 
Программа TAttooID применяется для идентификации личности по образцам татуировок из баз данных и видеозаписей, полицейских фотографий. Принцип работы программы основывается на идентификации ключевых моментов в образцах татуировок и позволяет проводить поиск членов одной бандитской группировки, которые очень часто набивают себе одинаковые тату. Французские полицейские с успехом применяют судебно-медицинский анализ татуировок и чернил для тату [5]. Судебно-медицинский анализ татуировок и чернил добавляют объективный компонент к интерпретации, идентификации и индивидуализации татуировок в ходе расследований.

Микробиологическая идентификация также является передовой технологией, это важный инструментом при раскрытии уголовных дел, связанных с сексуальным насилием. Сущность технологии состоит в том, что микробная ДНК у мужчин и женщин разная, что даёт возможность определить причастность лица к совершенному сексуальному преступлению.

Технология, которая основывается на измерении формы тела -морфометрия также является перспективной технологией и будущим криминалистики, особенно в деле определения скелетных останков пропавших людей. Эффективно криминалисты используют данную технологию при идентификации пропавших детей. Ярким примером может служить поиск пропавшего в 2009 году трёхлетнего Гуй Хао в городе Гуаньинь провинции Сычуань. Криминалисты полиции провинции Сычуань использовали нейронную сеть для распознания человеческих лиц независимо от возраста, результат приблизился к 96 \% точности. Благодаря такой технологии в 2019 году Гуй Хао был найден в провинции Гуандун [6]. Также технология распознавания лиц помогла найти спустя 30 лет пропавшего в двухлетнем возрасте Мао Иня. Система использует искусственный интеллект (ИИ) для определения пола и возраста на фотографиях.

В Индии с 2018 года в Нью-Дели полиция стала использовать систему распознавания лиц для поиска пропавших без вести детей. В Нью-Дели в указанном году числились пропавшими 45.000 детей. Всего в Индии числятся пропавшими без вести около 200 тысяч детей. За 2 года полиция обнаружила 2930 пропавших детей при помощи указанной технологии.

Еще одна новация - применение виртуальной аутопсии, она эффективно используется, если по религиозным или иным причинам члены семьи отказываются от проведения аутопсии, которая зачастую бывает необходима для поиска преступника. При виртуальной аутопсии физическое вскрытие не производится, используется трёхмерная модель, но такая процедура достаточно малоиспользуемая из-за сложностей в программировании и финансирования.

Но виртуальную аутопсию (виртопсию) исследователи называют прорывом в криминалистической визуализации. Такая методология разработана в Швейцарии. Её автор - Ричард Дирнхофер, директор Института судебной медицины в Берне. На такой открытие его натолкнуло судебное дело, которое рассматривалось в Цюрихе и касалось спорного момента - повреждения черепа жертвы гаечным ключом, что привело к смерти [7]. Методика нашла сторонников в Великобритании. В Манчестере, с разрешение родственников для установления причины смерти криминалисты делают МРТ и при помощи маркеров создаю трехмерное изображение с костями и внутренними органами.

Судебные патологоанатомы университета Лестера использовали компьютерную томографию для идентификации смертельных ударов, которые были нанесены королю Плантагенету Ричарду Третьему. Это методика подтолкнула радиологов и патологоанатомов из Цюриха использовать ее в комплексе с компьютерной томографией и МРТ для раскрытия убийств и идентификации смертельных ударов. 
Профессор Майкл Тали из Цюрихского института судебной медицины использует рентгеновские снимки, чтобы создавать трехмерные изображения неповреждённых трупов, ему принадлежит создание программы VirtoBot, эта программа позволяет выполнять точные заборы тканей посмертно, не подвергая патологоанатомов вредному излучению или опасности заражения. Технология исключает элементы субъективности.

K ней примыкает 3D-фотограммметрия - используется при сопоставлении оружия и иных объектов-автомобильных бамперов, бытовых предметов со смертельными травмами, которые были получены в случаях убийств или при несчастных случаях 3D-фотограмметрия позволяет визуализировать виртопсию. Ученые-криминалисты считают, что виртуальные вскрытия в будущем будут представляет собой обычную процедуру, результаты которой будут доступны сразу после выполнения.

Таким образом, проанализировав использование зарубежными странами таких новых криминалистических технологий и методик, как географическая криминалистика, микробиологический анализ отпечатков пальцев, Микробиологическая идентификация, система HirisPlex, виртуальная аутопсия, 3Dфотограммметрия, система распознавания лиц, морфометрия можно сделать вывод, что большинство инновационных технологии и методик не нашли своего отражения в криминалистике Российской Федерации и в данном случае можно было бы рассмотреть возможность их заимствования у иностранных государств. А те новейшие технологии и методики, которые уже применяются в Российской Федерации, в частности, методика распознавания лиц, следует усовершенствовать, ссылаясь также на успешный опыт зарубежных стран.

Но, при этом не стоит забывать, что все инновационных технологии требуют дальнейшего осмысления и разработки, они необходимы для развития криминалистики и решения задач, связанных с расследованием преступлений, с реальными потребностями практики в борьбе с преступностью.

Дальнейшее развитие криминалистической техники, методологии тесно связано с развитием информационных технологий, созданием автоматизированных поисковых систем и высокоточных приборов исследования образцов найденных на местах преступления, но важно отметить, что любое технологическое открытие должно быть подвергнуто анализу и неоднократной апробации.

$$
* * *
$$

1. Как полиция использует распознавание лиц и где это не удается // https://www.nytimes.com/2020/01/12/technology/facial-recognition-police.html.

2. Пастухов, П.С., Лосавио М. Использование информационных технологий для обеспечения безопасности личности, общества и государства // Вестник Пермского университета. Юридические науки. 2017. Вып. 36. С. 233.

3. Система распознавания лиц не идентифицировала бостонских террористов // https://www.securitylab.ru/news/439722.php.

4. Петренко А., Милушкин В. Наука на службе закона: криминалистика // https://biomolecula.ru/articles/nauka-na-sluzhbe-zakona-kriminalistika.

5. Мишель Д. Миранда Судебно-медицинский анализ татуировок и чернил для тату // https://www.taylorfrancis.com/books/forensic-analysis-tattoos-tattoo-inks-michelle-miranda.

6. Марсия Вендорф Технология распознавания лиц используется для поиска пропавших без вести детей // https://interestingengineering.com/facial-recognition-technology-is-being-used-to-find-missingchildren.

7. Петренко А., Милушкин В. Наука на службе закона: криминалистика // https://biomolecula.ru/articles/nauka-na-sluzhbe-zakona-kriminalistika. 